\title{
Ulnar-mammary syndrome
}

INSERM

\section{Source}

INSERM. (1999). Orphanet: an online rare disease and orphan drug data base. Ulnarmammary syndrome. ORPHA:3138

Ulnar-mammary syndrome (UMS) is a rare developmental disorder characterized by ulnar defects, mammary and apocrine gland hypoplasia and genital anomalies. Delayed puberty dental anomalies, short stature and obesity have also been described. 